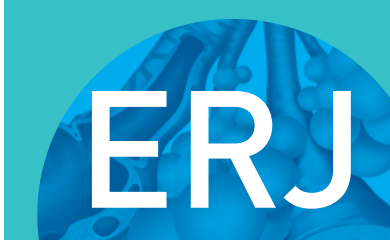

open research

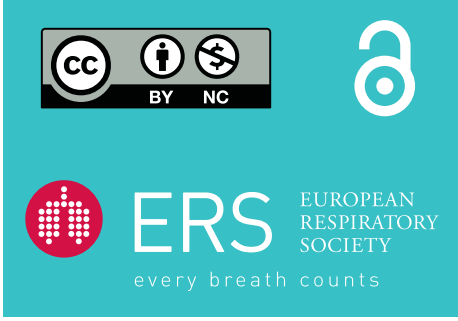

\section{Pulmonary hypertension in hereditary haemorrhagic telangiectasia is associated with multiple clinical conditions}

\section{To the Editor:}

Hereditary haemorrhagic telangiectasia (HHT) is a rare autosomal dominant vascular disorder. The prevalence of pulmonary hypertension $(\mathrm{PH})$ in the course of the disease is considered to be lower than $10 \%$ [1-4]. As previously reported, the increase in pulmonary arterial pressure in this setting may result from different mechanisms: isolated high flow state; $\mathrm{PH}$ due to left heart disease secondary to high cardiac output in the presence of hepatic arteriovenous malformations (post-capillary $\mathrm{PH}$, clinical classification group 2); or pulmonary vascular remodelling (pre-capillary $\mathrm{PH}$ ) [1-3]. For the latter mechanism, a diagnosis of heritable pulmonary arterial hypertension (group 1.2) could be applicable, as genetic mutations in the transforming growth factor- $\beta$ (TGF- $\beta$ ) signalling pathway $(A L K 1, E N G)$ are always found [5].

We hypothesised that several causes or risk factors may be associated in this genetically susceptible population to promote the occurrence of pre-capillary PH. Therefore, a study was conducted in HHT patients from a large single-centre cohort. During the study period (1995 to 2018), all eligible patients with a definite diagnosis of HHT referred to the French National Reference Centre for HHT (Lyon, France) were invited to participate in a prospective cohort. Data from pre-capillary $\mathrm{PH}$ patients were studied. This registry was set up in agreement with French bioethics laws.

Patients who underwent right heart catheterisation (RHC) had been classified into three haemodynamic profile subgroups according to current definitions of $\mathrm{PH}$ [6]: pre-capillary $\mathrm{PH}$ (mean pulmonary arterial pressure $(\mathrm{mPAP})>20 \mathrm{mmHg}$, pulmonary artery wedge pressure (PAWP) $\leqslant 15 \mathrm{mmHg}$, pulmonary vascular resistance (PVR) $\geqslant 3$ Wood Units (WU)), isolated post-capillary $\mathrm{PH}$ (mPAP $>20 \mathrm{mmHg}$, PAWP $>15 \mathrm{mmHg}$, PVR <3 WU) and combined pre- and post-capillary $\mathrm{PH}$ ( $\mathrm{mPAP}>20 \mathrm{mmHg}$, PAWP $>15 \mathrm{mmHg}$ and PVR $\geqslant 3 \mathrm{WU}$ ). Clinical data of patients with pre-capillary and combined PH have been reviewed with a focus on aetiological evaluation (pulmonary function tests, arterial blood gases, ventilation/perfusion lung scan, computed tomography, abdominal ultrasound scan and genetic testing).

Out of 901 consecutive patients with HHT, 313 underwent echocardiography for arteriovenous malformation screening or for dyspnoea. Depending on the echographic outcomes, 31 RHCs were performed at baseline. Among the 23 patients who had a $\mathrm{mPAP}>20 \mathrm{mmHg}$, one had isolated high pulmonary blood flow, eight out of 31 (25.8\%) had isolated post-capillary PH, eight out of 31 (25.8\%) had combined pre- and post-capillary $\mathrm{PH}$, and six out of 31 (19.3\%) had isolated pre-capillary PH (figure 1). Of 14 patients with pre-capillary and combined $\mathrm{PH}, 12$ were female: male-to-female ratio 0.17 versus 0.68 in HHT patients without PH ( $\mathrm{p}=0.047)$. The mean (SD) age at PH diagnosis was 66.3 (9.9) years. PH was discovered $38( \pm 52)$ months after HHT diagnostics were performed.

Multiple clinical conditions that could have contributed to $\mathrm{PH}$ pathogenesis were identified in 12 out of 14 patients with pre-capillary PH (86\%) (table 1): 1) Genetic mutations in the TGF- $\beta$ signalling pathway ( $A L K 1 \mathrm{n}=12, E N G \mathrm{n}=2)$ were present in all cases. Mutation ALK1, exon 8, c.1112 dup was found in eight

@ERSpublications

Multiple clinical conditions are combined with genetic mutations to contribute to the development of pulmonary vascular remodelling in hereditary haemorrhagic telangiectasia. A systematic aetiological evaluation is required for these patients. https://bit.ly/34V7HPy

Cite this article as: Margelidon-Cozzolino V, Cottin V, Dupuis-Girod S, et al. Pulmonary hypertension in hereditary haemorrhagic telangiectasia is associated with multiple clinical conditions. ERJ Open Res 2021; 7: 00078-2020 [https://doi.org/10.1183/23120541.00078-2020]. 


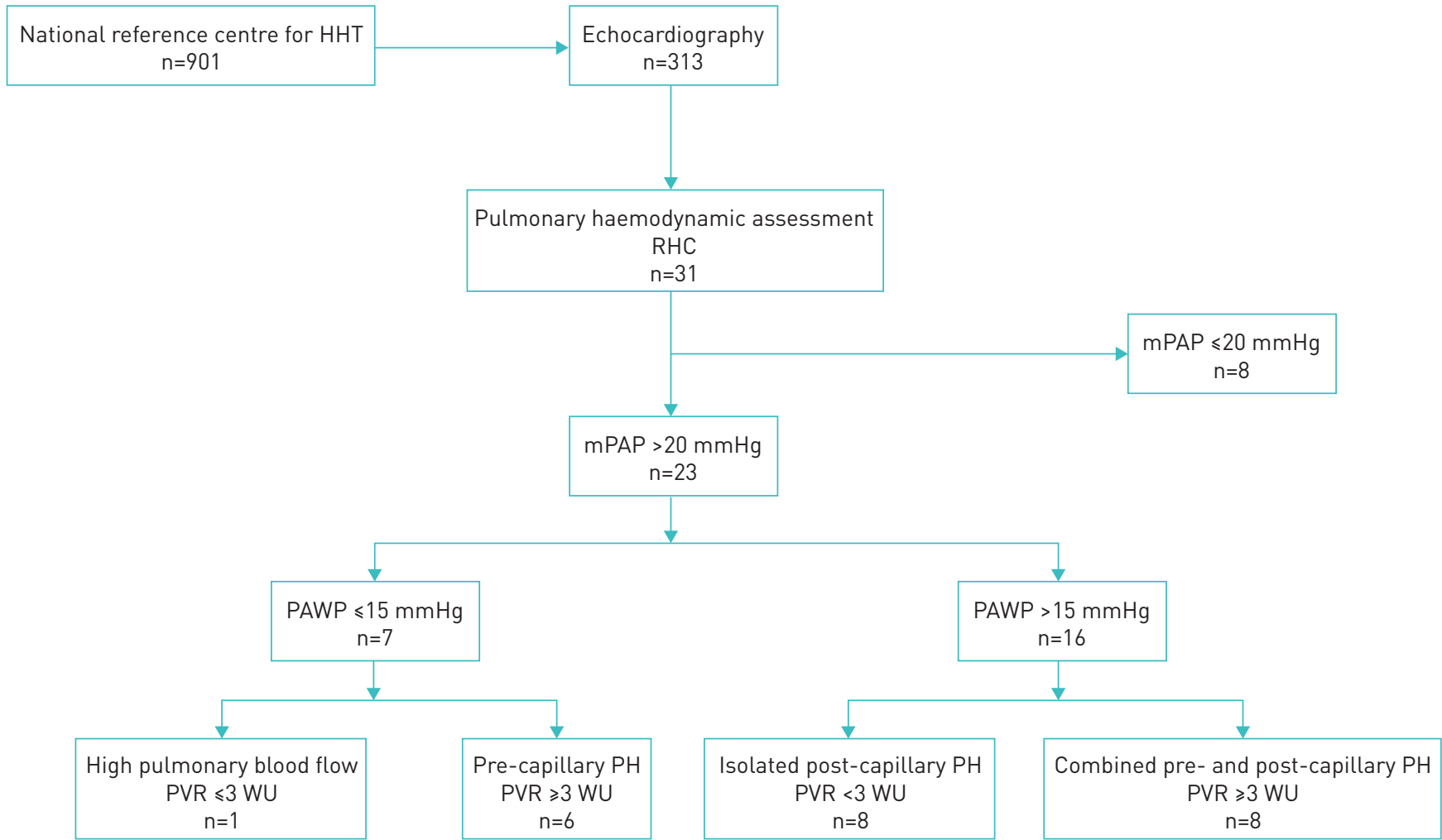

FIGURE 1 Flow chart. HHT: hereditary haemorrhagic telangiectasia; RHC: right heart catheterisation; mPAP: mean pulmonary arterial pressure; PAWP: pulmonary artery wedge pressure; PVR: pulmonary vascular resistance; PH: pulmonary hypertension: WU: Wood units.

out of 14 patients (57\%). 2) Chronic lung disease with a forced expiratory volume in $1 \mathrm{~s}\left(\mathrm{FEV}_{1}\right)<60 \%$ or a forced vital capacity (FVC) $<70 \%$ was found in six patients (linked to three restrictive and three obstructive pulmonary diseases, associated with severe hypoxaemia in two of them). 3) Portal hypertension related to hepatic fibrosis was present in one patient. 4) Four patients also had significant perfusion defects on ventilation - perfusion lung scintigraphy and thromboembolic patterns on computed tomography. 5) A hyperkinetic state was observed in three patients. 6) Left heart failure was further noted in eight individuals (table 1). Overall, six patients (43\%) had three or more potential risk factors for PH.

The combination of multiple potential risk factors for $\mathrm{PH}$ was striking since the vast majority (86\%) of patients with $\mathrm{PH}$ exhibited multifactorial mechanisms. Therefore, a systematic aetiological evaluation is required to guide management. Even if genetic mutations in the TGF- $\beta$ signalling pathway can participate in PH development, additional factors might have contributed, especially frequent left heart failure (group $2 \mathrm{PH}$ ). Indeed, chronic increase of pulmonary flow due to left-to-right shunt may lead, as in Eisenmenger syndrome, to pulmonary vascular remodelling in the long term [7]. Chronic lung disease and chronic thromboembolic disease may also have significantly increased the risk of $\mathrm{PH}$ in this HHT population (group 3 and $4 \mathrm{PH}$, respectively). It is noteworthy that HHT patients have an increased risk of thrombosis $[8,9]$. It has been reported that environmental risk factors such as methamphetamine or dexfenfluramine exposure had contributed to the development of PH in HHT patients [10, 11]. In our study, exposure to drugs and toxins was not systematically assessed and may have been underestimated. These findings are reminiscent of other aetiological contexts in patients with $\mathrm{PH}$, in which several comorbidities and cofactors can contribute to increase the risk of PH - patients with HIV infection, hepatitis liver disease, interferon therapy and illicit drug intake, for example [12].

The large female predominance noticed here has previously been reported [4]. Epidemiological data of both heritable $\mathrm{PH}$ and HHT demonstrate female predominance. In some studies, hepatic arteriovenous malformations and ALK1 mutations were also more common in women than in men with HHT [13], leading to the hypothesis that female sex hormones may affect vascular remodelling.

Limitations in our study included the retrospective design, although the data were collected prospectively in a national HHT registry at the time of each hospitalisation. The study was monocentric but included a relatively large cohort of patients from a tertiary referral HHT centre. In this large cohort, only a few subjects 
TABLE 1 Haemodynamic, genetic and clinical characteristics of patients with pre-capillary and combined pulmonary hypertension

\begin{tabular}{|c|c|c|c|c|c|c|c|c|c|c|c|c|c|}
\hline $\begin{array}{l}\text { Sex/ } \\
\text { age } \\
\text { years }\end{array}$ & $\begin{array}{l}\mathrm{mPAP} \\
\mathrm{mmHg}\end{array}$ & $\begin{array}{l}\text { PAWP } \\
\mathrm{mmHg}\end{array}$ & $\begin{array}{c}\text { Cardiac } \\
\text { index } \\
\mathrm{L} \cdot \mathrm{min}^{-1} \cdot \mathrm{m}^{-2}\end{array}$ & $\begin{array}{l}\text { PVR } \\
\text { WU }\end{array}$ & $\underset{g \cdot d L^{-1}}{H b}$ & $\begin{array}{l}\text { Mutation gene, exon, } \\
\text { nucleotide, change }\end{array}$ & AVM & $\begin{array}{l}\mathrm{FEV}_{1} \mathrm{~L} \\
(\% \text { pred })\end{array}$ & $\begin{array}{l}\text { FVC L } \\
\text { (\% pred) }\end{array}$ & $\begin{array}{l}\text { TLC L } \\
\text { (\% pred) }\end{array}$ & $\begin{array}{c}P_{\mathrm{aO}_{2}} \\
\mathrm{mmHg}\end{array}$ & CTEPH & $\begin{array}{l}\text { Classification } \\
\text { subgroups }\end{array}$ \\
\hline$F / 67$ & 36 & 10 & 4.1 & 3.8 & 10.7 & $E N G, 4, c .446, G>A$ & $\mathrm{H}$ & $1.93(94 \%)$ & $\begin{array}{c}2.71 \\
(105 \%)\end{array}$ & $4.33(91 \%)$ & 72.7 & - & $1.2+\mathrm{HS}$ \\
\hline$F / 46$ & 29 & 9 & 3.2 & 3.1 & 14.8 & $A L K 1,4, c .470, C>T$ & $\mathrm{H}$ & $1.54(53 \%)$ & $2.01(58 \%)$ & $4.92(93 \%)$ & 93 & & $1.2+3$ \\
\hline$F / 82$ & 48 & 9 & 3.1 & 6.8 & 13.8 & $A L K 1,8$, c. 1112 , dup & $\mathrm{H}$ & $1.80(84 \%)$ & $\begin{array}{c}2.80 \\
(103 \%)\end{array}$ & $\begin{array}{c}5.20 \\
(102 \%)\end{array}$ & 99 & - & $1.2+4$ \\
\hline$F / 68$ & 24 & 13 & 2.3 & 3.2 & 11.3 & $A L K 1,3$, c. $102, C>A$ & $\mathrm{P}+\mathrm{H}$ & $1.56(92 \%)$ & $2.03(93 \%)$ & $3.68(85 \%)$ & 89.2 & & 1.2 \\
\hline M/77 & 34 & 20 & 1.9 & 4.8 & 12.4 & ENG, 12, c. $1522, C>T$ & & $0.86(43 \%)$ & $2.34(86 \%)$ & $4.75(88 \%)$ & 81 & - & $1.2+2+3+4$ \\
\hline M/55 & 53 & 23 & 3.7 & 4.9 & 9.2 & ALK1, 8, c.1112, dup & $P$ & $0.49(17 \%)$ & $\begin{array}{c}0.80 \\
(21.5 \%)\end{array}$ & $2.67(45 \%)$ & 44.2 & & $1.2+2+3$ \\
\hline F/71 & 49 & 21 & 4.6 & 4.0 & & ALK1, 8, c.1112, dup & $\mathrm{P}+\mathrm{H}$ & $0.79(37 \%)$ & $1.13(44 \%)$ & & & & $1.2+2+3+\mathrm{HS}$ \\
\hline$F / 57$ & 30 & 18 & 2.1 & 3.4 & 13.1 & $A L K 1,7, c .956, G>A$ & & $2.28(97 \%)$ & $\begin{array}{c}3.33 \\
(117 \%)\end{array}$ & $\begin{array}{c}5.66 \\
(117 \%)\end{array}$ & 81 & & $1.2+2$ \\
\hline$F / 63$ & 53 & 28 & 4.3 & 3.1 & 9 & $A L K 1,3$, c. $140, G>C$ & $\mathrm{H}$ & & & & & & $\begin{array}{c}1.2+1.4 .3+2 \\
+\mathrm{HS}\end{array}$ \\
\hline \multicolumn{14}{|c|}{$\begin{array}{l}\text { mPAP: mean pulmonary arterial pressure; PAWP: pulmonary artery wedge pressure; PVR : pulmonary vascular resistance; WU: Wood units; } \\
\mathrm{Hb} \text { : haemoglobin; } \mathrm{AVM} \text { : arteriovenous malformation; } \mathrm{FEV}_{1} \text { : forced expiratory volume in } 1 \mathrm{~s} ; \mathrm{FVC} \text { : forced vital capacity; TLC: total lung capacity; } \\
P_{\mathrm{aO}} \text { : arterial oxygen tension; CTEPH: chronic thromboembolic pulmonary hypertension; F: female; M: male; dup: duplication; H: hepatic; } \\
\mathrm{P}: \text { pulmonary; } 1.2 \text { : heritable pulmonary hypertension; } 1.4 .3 \text { : portal hypertension; } 2 \text { : left heart diseases; } 3: \text { lung diseases; } 4: \text { pulmonary artery } \\
\text { obstruction; HS: hyperkinetic state. }\end{array}$} \\
\hline
\end{tabular}

underwent an RHC. This was probably due to the fact that transthoracic echocardiography was not performed systematically but only when arteriovenous malformation screening was conducted or when $\mathrm{PH}$ was clinically suspected. Therefore, it cannot be excluded that pre-capillary PH could have been underestimated, although results were consistent with previous data [1-4]. Finally, the ALK1 gene mutation c.1112 dup was frequently found due to the founder effect described in the Rhône-Alpes region [14].

In conclusion, multiple clinical conditions combine with genetic mutations to contribute to the development of $\mathrm{PH}$ in HHT patients. This finding highlights how critical a systematic aetiological evaluation could be, and various management strategies could result from it.

Victor Margelidon-Cozzolino ${ }^{1,2}$, Vincent Cottin $\odot^{2}$, Sophie Dupuis-Girod ${ }^{3}$, Julie Traclet $^{2}$, Kais Ahmad ${ }^{2}$, Jean-François Mornex ${ }^{2}$ and Ségolène Turquier ${ }^{1,2}$

${ }^{1}$ Dept of Respiratory Physiology, Hospices Civils de Lyon, Louis Pradel Hospital, Lyon, France. ${ }^{2}$ Competence Centre for Severe Pulmonary Hypertension, Reference Centre for Rare Pulmonary Diseases, Dept of Respiratory Medicine, Hospices Civils de Lyon, Louis Pradel Hospital, UMR754, Claude Bernard University Lyon 1, Lyon, France. ${ }^{3}$ National Reference Centre for Hereditary Hemorrhagic Telangiectasia, Dept of Genetic Medicine, Hospices Civils de Lyon, Louis Pradel Hospital, Lyon, France and Univ. Grenoble Alpes, Inserm, CEA, BIG-Biologie du Cancer et de l'Infection, Grenoble, France.

Correspondence: Ségolène Turquier, Dept of Respiratory Physiology, Louis Pradel Hospital, 28 avenue du doyen Lépine, 69500 Bron, France. E-mail: segolene.turquier@chu-lyon.fr

Received: 2 March 2020 | Accepted after revision: 9 Oct 2020

This study was presented as a presentation/abstract publication at the CPLF conference in January 2019, in Marseille, France, and the European Respiratory Society International Congress in September 2019, in Madrid, Spain.

Conflict of interest: V. Margelidon-Cozzolino reports non-financial support for travel to medical meetings from Actelion and Vitalaire outside the submitted work. V. Cottin reports advisory board and lecture fees, and travel support from Actelion; grants, consultancy and lecture fees, and travel support from Boehringer Ingelheim and Roche; advisory board and data safety monitoring board (DSMB) fees from Bayer/MSD and Galapagos; advisory board and lecture fees from Novartis; 
lecture fees from Sanofi; DSMB and steering committee fees from Promedior; and DSMB fees from Celgene and Galecto, all outside the submitted work. S. Dupuis-Girod has nothing to disclose. J. Traclet reports travel to medical meetings supported by Roche, Boehringer Ingelheim, CSL Behring and Actelion, and lecture fees from Actelion, outside the submitted work. K. Ahmad reports lecture fees and invitations to medical meetings from Actelion and from Roche, and invitations to medical meetings from Boehringer Ingelheim, outside the submitted work. J.F. Mornex reports consultancy fees from LFB Biomedicaments and CSL Behring, lecture fees and travel support from Actelion, consultancy fees from Adene, travel support from Agiradom and Amgen, travel support and lecture fees from Boehringer Ingelheim and Roche, and travel support from Novartis, Pfizer and Vitalaire, outside the submitted work. S. Turquier reports lecture fees and a congress invitation from Actelion, and a congress invitation from Vitalaire, outside the submitted work.

\section{References}

1 Revuz S, Decullier E, Ginon I, et al. Pulmonary hypertension subtypes associated with hereditary hemorrhagic telangiectasia: hemodynamic profiles and survival probability. PLoS One 2017; 12: e0184227.

2 Lyle MA, Fenstad ER, McGoon MD, et al. Pulmonary hypertension in hereditary hemorrhagic telangiectasia. Chest 2016; 149: 362-371.

3 Dupuis-Girod S, Cottin V, Shovlin CL. The lung in hereditary hemorrhagic telangiectasia. Respiration 2017; 94: 315-330.

4 Harder EM, Fares WH. Hospitalizations with hereditary hemorrhagic telangiectasia and pulmonary hypertension in the United States from 2000 to 2014. Respir Med 2019; 147: 26-30.

5 Trembath RC, Thomson JR, Machado RD, et al. Clinical and molecular genetic features of pulmonary hypertension in patients with hereditary hemorrhagic telangiectasia. N Engl J Med 2001; 345: 325-334.

6 Simonneau G, Montani D, Celermajer DS, et al. Haemodynamic definitions and updated clinical classification of pulmonary hypertension. Eur Respir J 2019; 53: 1801913.

7 Rabinovitch M. Pulmonary hypertension: pathophysiology as a basis for clinical decision making. J Heart Lung Transplant 1999; 11: 1041-1053.

8 Shovlin CL, Sulaiman NL, Govani FS, et al. Elevated factor VIII in hereditary haemorrhagic telangiectasia (HHT): association with venous thromboembolism. Thromb Haemost 2007; 98: 1031-1039.

9 Riera-Mestre A, Mora-Lujan JM, Trujillo-Santos J, et al. Natural history of patients with venous thromboembolism and hereditary hemorrhagic telangiectasia. Findings from the RIETE registry. Orphanet J Rare Dis 2019; 14: 196.

10 Ayala E, Kudelko KT, Haddad F, et al. The intersection of genes and environment: development of pulmonary arterial hypertension in a patient with hereditary hemorrhagic telangiectasia and stimulant exposure. Chest 2012; 141: $1598-1600$.

11 Chaouat A, Coulet F, Favre C, et al. Endoglin germline mutation in a patient with hereditary haemorrhagic telangiectasia and dexfenfluramine associated pulmonary arterial hypertension. Thorax 2004; 59: 446-448.

12 Traclet J, Khouatra C, Piegay F, et al. Pulmonary arterial hypertension in heroin users. J Heart Lung Transplant 2016; 35: 932-934.

13 Girerd B, Montani D, Coulet F, et al. Clinical outcomes of pulmonary arterial hypertension in patients carrying an ACVRL1 (ALK1) mutation. Am J Respir Crit Care Med 2010; 181: 851-861.

14 Lesca G, Genin E, Blachier C, et al. Hereditary hemorrhagic telangiectasia: evidence for regional founder effects of ACVRL1 mutations in French and Italian patients. Eur J Hum Genet 2008; 16: 742-749. 